\title{
O ENSINO DE CIÊNCIAS COMO FERRAMENTA PEDAGÓGICA DE RECONSTRUÇÃO DAS REPRESENTAÇÕES ESCOLARES SOBRE OS POVOS
}

\author{
INDÍGENAS
}

\author{
Cleise Helen Botelho Koeppe* \\ Regina Maria Rabello Borges** \\ Regis Alexandre Lahm***
}

RESUMO: As representações escolares sobre os povos indígenas perpetuam práticas sociais históricas. A construção de uma concepção cidadã a respeito dos desses grupos demanda a identificação, a problematização e a reformulação dessas representações perpetuadas, também, no âmbito escolar. Neste artigo, discute-se o processo de reformulação representacional a partir de atividades curriculares de ciências, desenvolvidas junto a um grupo de estudantes do Ensino Fundamental, visando a desmistificação de conceitos associados às etnias indígenas. Ao término da pesquisa, novas concepções foram desenvolvidas pelos educandos, em uma perspectiva educacional contextualizada, concluindo-se que essa elaboração conceitual é idiossincrática e contínua.

Palavras-chave: Representações. Educação em ciências. Etnias indígenas brasileiras contemporâneas.

\section{SCIENCE TEACHING AS A TOOL FOR THE RECONSTRUCTION OF INDIGENOUS REPRESENTATIONS AT THE SCHOOL ENVIRONMENT}

ABSTRACT: The school representations of indigenous peoples perpetuate historical social practices. The construction of a civic conception regarding these groups demands identification, questioning and reformulation of such representations in the school environment. In this article, we discuss the process of representational reformulation starting from curricular activities in science, developed with a group of elementary school students. The same aims to demystify the concepts associated with indigenous groups. At the end of this research, new concepts were developed by students in a contextualized educational perspective, leading to the conclusion that conceptual elaboration is idiosyncratic and continuous.

Keywords: Representations. Science Education. Contemporary Brazilian Indigenous Groups.

\footnotetext{
*Pós-Graduação Lato Sensu em Supervisão Educacional pela Associação dos Supervisores em Educação do Rio grande do Sul, Mestre em Educação em Ciências e Matemática pela Pontifícia Universidade Católica do Rio Grande do Sul - PUCRS. Professora de ciências químicas, físicas e biológicas na Rede Municipal de Ensino de Gravataí - Rio Grande do Sul. E-mail: cleise.koeppe@acad.pucrs.br

** Doutora em Educação Pela Pontifícia Universidade Católica PUCRS. Professora Permanente do Programa de Pós - Graduação em Ciências e Matemática da PUCRS. E-mail: rborges@pucrs.br

***Doutor e Recursos Hídricos e
Saneamento Ambiental pela
Universidade Federal do Rio
Grande do Sul- UFRGS. Professor
Permanente do Programa de Pós
Graduação em Ciências e
Matemática da PUCRS. E- mail:
lahm@pucrs.br
lahm@pucrs.br
} 


\section{INTRODUÇÃO}

Os meios de comunicação, atualmente, têm dado bastante destaque aos povos indígenas. Reportagens, frequentemente associadas a conflitos, são cada vez mais comuns, alimentando as discussões a respeito desses grupos, na maioria das vezes, representados social e culturalmente de maneira estereotipada.

Dentro do âmbito escolar, a temática indígena costuma estar relacionada às ciências humanas, entretanto, sua abordagem interdisciplinar é recomendada pelos Parâmetros Curriculares Nacionais - PCN - Pluralidade Cultural (BRASIL, 1997) como estratégia para a construção de uma sociedade fraterna, justa e livre; e reforçada pela Lei 11.645/08 (BRASIL, 2008) que determina a obrigatoriedade do estudo da história e da cultura indígenas em todos os estabelecimentos de educação básica do país.

Inserir a temática indígena no currículo de ciências corrobora para a importância do processo educacional no desenvolvimento de novos conceitos éticos, atitudinais e comportamentais em relação a esses grupos, promovendo a problematização das representações escolares equivocadas consolidadas ao longo dos anos. O contexto escolar atual, na contramão do proposto pelo PCN - Pluralidade Cultural (BRASIL, 1997), prioriza o conhecimento e a visão europeia nas diversas áreas de conhecimento. $\mathrm{Na}$ escola contemporânea, o universalismo do conhecimento ocidental sobrepuja as demais formas de conhecimento desenvolvidas secularmente pelas diversas civilizações que participaram e participam do mundo moderno (TREZ, 2011). É nessa prática educacional que são criados preconceitos, racismos e obstáculos ao desenvolvimento de um espírito solidário (BANIWA, 2006).

Desapropriadas de seus saberes, minorias étnicas que compõem a população brasileira permanecem relegadas ao segundo plano. Associadas a contribuições exóticas ou folclóricas, recebem menor importância do que lhes é de direito, além de serem vítimas de representações culturais estereotipadas.

As palavras relacionadas a esses grupos encontram-se impregnadas de significações culturais e produzem simbologias e representações arraigadas no imaginário das sociedades (HALL, 1997). A simples menção da palavra indio forma, na mente dos estudantes, uma imagem característica: nu, abrigado pela floresta e ornamentado com elementos naturais.

Baniwa (2006) e Grupioni (2001) são alguns dos pesquisadores que questionam a denominação índio, por eles considerada genérica e não contempladora das diversidades culturais existentes entre as muitas etnias indígenas que constituem o povo brasileiro. Baniwa (2006) relaciona esse termo ao erro de interpretação de Cristóvão Colombo quando chegou à América em busca de uma rota alternativa para a Índia. Nesse ínterim, o autor refuta essa palavra pela sua generalidade, mas, mesmo assim, descreve três diferentes representações socioculturais a ela associadas. A primeira delas, a representação romântica, descreve o nativo como um ser inocente, puro, selvagem e elemento constituinte da floresta, imagem que persiste nos dias atuais e fomenta 
políticas públicas paternalistas como, por exemplo, a criação da FUNAI. A segunda representa o indio cruel, agressivo, canibal, preguiçoso e traiçoeiro, uma visão também constituinte do imaginário popular contemporâneo e que fundamenta massacres, além de outras ações restritivas e preconceituosas em relação aos povos nativos. A terceira representação, ao contrário das duas anteriores, não tem sua origem no contexto colonial eurocêntrico brasileiro, mas na Constituição de 1988, quando cidadãos indígenas foram reconhecidos, sendo assegurado a eles o direito de cultivar seus hábitos, valores e o acesso à tecnologia e às outras culturas.

Representações mistas, fortemente enraizadas nos ambientes escolares e sociais, são difundidas por livros didáticos e pelos veículos de comunicação (GRUPIONI, 2001). Elas atendem aos interesses de uma elite dominante e originam contradições, ambiguidades e preconceitos sobre o mundo indígena, ignorado pelos indivíduos ditos "civilizados" (BANIWA, 2006). Os textos educacionais descrevem os povos nativos segundo a visão histórica ocidental, reforçando o menosprezo e o racismo. Tanto a mídia analógica como a digital veiculam notícias de massacres, violência e conflito.

Representações e concepções derivam da compreensão e do entendimento de signos e fatos cotidianos. Elaboradas a partir de um contexto universal e sofrendo influência da realidade social, política e cultural vivenciada pelo aluno em seu cotidiano, podem ser reconhecidas dentro do espaço escolar. Essa nova interpretação, fruto da interação entre a experiência sociocultural e o "conhecimento científico" desenvolvido na escola, é considerada por Pastoriza (2011) como uma representação escolar.

Neste artigo, serão descritas estratégias pedagógicas desenvolvidas nas aulas de Ciências, cujos objetivos foram identificar, problematizar e buscar a reformulação das representações indígenas dos estudantes de uma turma de sétimo ano do Ensino Fundamental.

\section{METODOLOGIA}

É possível caracterizar esta pesquisa como um estudo de caso qualitativo, apoiando-se na definição proposta por André (1984, p. 51-52) segundo a qual essa metodologia consiste em uma forma particular de estudo em uma instância específica, que pretende "retratar o idiossincrático e o particular como legítimos em si mesmos". Assim, este trabalho busca analisar as concepções dos sujeitos sobre um tema de relevância social - as representações socioculturais indígenas - e investigar como esses sujeitos se apropriaram de novas informações para reformulá-las. Trinta e seis educandos, pertencentes à faixa etária compreendida entre onze e quinze anos, regularmente matriculados no sétimo ano do Ensino Fundamental de uma escola do município de Gravataí-RS, no Rio Grande do Sul, foram os sujeitos desta pesquisa. As atividades, distribuídas ao longo do período letivo, foram aplicadas como estratégias pedagógicas para o desenvolvimento dos conteúdos programáticos de Ciências, considerando o fato de uma das autoras ser, também, a professora regente dessa turma. 
Buscando preservar a identidade dos sujeitos, solicitou-se que cada um escolhesse um codinome indígena a partir de uma listagem coletada na internet. Para contemplar a diversidade étnica indígena brasileira, os educandos dividiram-se em pequenos grupos de trabalho e cada grupo escolheu, considerando o bioma brasileiro que habitam, uma ou duas etnias para aprofundar a investigação: Guarani e Kaingang (Rio Grande do Sul RS - e Santa Catarina - SC), Juruna (Mato Grosso - MT), Kayapó (leste de Mato Grosso), Kaxinawá (Acre - AC), Matis e Marubo ( Amazonas - AM), Suruí (Rondônia - RO), Ye'kuana (Roraima - RR) e Karajá (Tocantins - TO).

O material coletado é composto por desenhos, textos escritos e relatos transcritos no diário de campo da autora, produzidos no decorrer das atividades desenvolvidas. Os textos escritos e relatos foram analisados seguindo os parâmetros ditados pela "Análise Textual Discursiva" (MORAES; GALIAZZI, 2007) e os desenhos, devido à sua complexidade de informações, por meio da análise semiótica proposta por Barthes (1971).

Dessas análises, emergiram categorias que permitiram compreender o processo de identificação, problematização e reformulação das representações indígenas constatadas dentro do grupo. As categorias emergentes orientaram a discussão dos resultados doravante descritos sob dois enfoques: Ferramentas tecnológicas e problematização das representações indigenas e Etnociências e valorização da cultura indigena. A dinâmica da prática efetivada na sala de aula e a análise do material produzido pelos sujeitos passam a ser descritas a seguir.

\section{RESULTADOS E DISCUSSÃO}

O dia 19 de abril costuma ser lembrado nas escolas infantis. Nessa ocasião, as crianças têm seu rosto pintado, fantasiam-se de indiozinhos colocando cocares e tangas improvisadas com penas de papel e entoam músicas inocentes e divertidas. Os níveis educacionais posteriores pouca ou nenhuma atenção dispensam aos povos indígenas nessa data. Na escola onde ocorreu esta pesquisa, o Dia do Índio serviu de inspiração para uma atividade interdisciplinar denominada Feira das Culturas, momento em que os alunos seriam incentivados a mostrar para a comunidade um estudo sobre as contribuições indígenas para a formação da sociedade brasileira, temática tão rica que despertou o interesse dos educandos para desenvolvimento dos conteúdos de Ciências pelo restante do ano letivo.

Quando da proposição do trabalho junto aos sujeitos, foi possível detectar a visão estereotipada do indígena brasileiro, relacionada ao conceito do bom selvagem. Por vezes, eles dramatizavam situações relacionadas ao imaginário popular, tais como sons guturais, manuseio de arco e flecha, ou interesse acentuado em observar imagens de nus indígenas. Tais atitudes despertaram a necessidade de reformular a visão caricata e preconceituosa que permeia o tema indio na educação atual. "A imagem de um índio genérico, que vive nu na mata, mora em ocas e tabas, cultua Tupã e Jaci e fala tupi, predominante no senso comum [...]." (GRUPIONI, 2001, p.11). 
Os relatos coletados descrevem índios que sobrevivem isolados na mata e que, ao entrarem em contato com os não indios, são escravizados ou massacrados, como pode ser exemplificado pelos relatos de Aimberê e Apuena, respectivamente:

\begin{abstract}
As tribos ficam no interior porque a vegetação é natural e lá eles plantam e comem. E lá o homem branco não chega e dai ele quer ensinar as coisas dele e dai vai se extinguindo e vai acabando a cultura. E os indios estão sobrevivendo por causa da floresta que tem alimento e água e é dificil das pessoas de fora chegar lá e tem lugares para se esconder dos homens brancos e para continuar a nossa antiga cultura dos indios.
\end{abstract}

Porque foram extintos bá muito tempo na descoberta do Brasil existiam muitas tribos na praia. Quando os brancos chegaram levaram todos do litoral para escravizar. São aldeias indígenas onde os homens brancos podem entrar e influenciar os indios a não seguirem sua cultura religiosa. Faz. com que os indios não queiram mais seguir a cultura indigena. Na floresta tem lugar para os indios se esconderem.

As concepções a respeito das etnias indígenas remontam ao período colonial, quando o índio passou a ser considerado como um indivíduo uno, ao mesmo tempo ingênuo e agressivo, conhecedor dos segredos naturais de um ambiente ora idílico, ora ameaçador. A perplexidade do europeu ao se deparar com essa nova e exótica cultura produziu a representação de uma nação selvagem, inocente e, por isso, passível de ser dominada, explorada e destruída (ARRUDA, 2002).

Essa representação que associa o índio à natureza encontra-se incrustada em nosso imaginário a ponto de desconstituir o indígena como tal caso ele não esteja adornado de penas, vestindo tanga, cultuando Jaci, comendo mandioca e navegando em canoas rústicas. Grupioni (2001, p. 13) cita essa ideia equivocada como derivada da descrição apresentada pelos livros didáticos e do hábito de situar os indígenas no passado histórico, e alerta:

À medida que a realidade se transforma, o homem busca novos símbolos que possam traduzir o significado das novas realidades. $\mathrm{O}$ fato de consumir produtos industrializados, de dominar novas técnicas e novos conhecimentos, não faz com que uma sociedade deixe de ser indígena.

A interpretação pode resultar em consolidação de estereótipos, de caricaturas e da marginalização do indígena brasileiro. Para Tassinari (1995) é dever da escola fornecer informações corretas e desprovidas de visões preconceituosas que auxiliem no reconhecimento da realidade político-social do país e na superação de preconceitos e estereótipos, promovendo a reflexão e o protagonismo dos alunos em relação à construção do futuro de uma nação com cidadãos capazes de reconhecer e valorizar as diferenças culturais.

A representação cultural indígena do bom selvagem, associada à concepção de indio genérico, é bastante difundida na sociedade contemporânea e surgiu de maneira unânime no grupo de sujeitos durante a etapa de introdução das atividades.

O mito do bom selvagem, inspirado em Rousseau, atribui aos índios um estado de consciência selvagem que os torna incapazes de distinguir entre o bem e o mal, devido ao distanciamento com o regramento civilizado europeu. Assim, essa inocência 
quase infantil provoca ações regidas pelos instintos naturais (NOVAES, 1999), e dessa forma desperta, em relação a essas etnias, sentimentos de compaixão ou de pseudoproteção legitimadores da aculturação.

O indio genérico é uma representação social forte, desenvolvida pelas relações de poder iniciadas no período colonial brasileiro e perpetuada pela mídia e manuais didáticos (ARRUDA, 2002; GRUPIONI, 2001; BANIWA, 1996). Deriva do processo de aculturação que, segundo Kreutz (1999, p. 84), foi um "artifício de domínio do europeu, cristão-colonizador, para tornar os povos com culturas diferentes mais iguais a ele para colocá-los melhor a seu serviço". Homogeneizar para subjugar é uma estratégia descrita por Gusmão (1999. p.44) como:

[...] inventada pelos brancos para, desrespeitando a especificidade de cada grupo, colocá-los todos, 'no mesmo saco'[...]. Desconsidera-se aí, o que são de fato e o que pensam sobre si mesmos como componentes de uma história singular de grupo que tem suas próprias marcas, portadoras de significados, sentidos e visão do mundo, únicos porque só seu. Chamá-los de índios indistintamente é negar-lhes o que de mais interior os habita [...].

De acordo com o Censo de 2010 (IBGE), existem, atualmente, no Brasil, 305 etnias indígenas, possuidoras de valores culturais diversos e vivendo em diferentes biomas.

\section{Ferramentas tecnológicas e problematização das representações}

Uma abordagem pedagógica importante para a desconstrução dessas representações difundidas pelo senso comum pode ser a comparação dos hábitos culturais indígenas com os do homem urbano. Entretanto, a complexidade e a variedade multicultural existente entre as etnias dificultam essa prática. Além disso, a maioria das etnias indígenas brasileiras contemporâneas habitam locais de difícil acesso, praticamente inviabilizando uma aproximação comparativa.

Para superar essas dificuldades decorrentes da distância espacial foram propostas atividades utilizando, como recursos principais, as Tecnologias de Informação e Comunicação - TICs -, e as mídias atuais, ferramentas que podem ser considerados aliadas no processo de ensino-aprendizagem, proporcionando sua modernização e contextualização (KOEPPE; LAHM; BORGES, 2013).

Para essa etapa da pesquisa, as atividades propostas foram: seleção das etnias por sua localização geográfica; coleta de informações sobre os diferentes povos selecionados; seleção, impressão e análise da imagem orbital de uma aldeia de cada etnia; elaboração de maquetes e cartazes representativos das etnias abordando as relações destas com o meio ambiente do entorno.

Ao coletarem informações para elaborarem maquetes e cartazes, os educandos passaram a referir-se às etnias investigadas com a expressão minha tribo, o que acusa o embrião de uma sensação de pertencimento a essas etnias, derivada da convivência proporcionada pela investigação nos meios digitais, e que pode ser interpretada como a gênese de um mecanismo de identificação pessoal com os hábitos culturais e ambientais desses povos. 
O trabalho com imagens das aldeias permitiu o contato com paisagens desconhecidas, atualizadas e, muitas vezes, ausentes nos livros didáticos. Assim, o sensoriamento remoto $^{1}$ transformou-se em uma ferramenta didática diversificadora e dinâmica capaz de incentivar discussões impensadas se a única fonte de informação fosse o livro didático.

A opção pela utilização de imagens orbitais apoia-se no discurso de Santos, Lahm e Borges (2009, p.97) ao afirmarem que: "Talvez as imagens supram lacunas que antes a linguagem escrita não havia preenchido. A imagem propõe uma visão alternativa e provoca reflexão, novas impressões, ao invocar outros sentidos".

Partindo da observação criteriosa das imagens orbitais, o grupo de alunos levantou questionamentos referentes a conceitos estruturais: elementos relevantes na construção das habitações e formações geométricas características das aldeias; conceitos ambientais: proximidade de recursos hídricos, de formações vegetais e impactos ambientais significativos; e conceitos culturais: identificação de elementos urbanos nos arredores, associando-as às etnias investigadas.

Uma visão crítica e mais atual das etnias indígenas brasileiras foi elaborada após a interpretação das imagens apresentadas. Em suas falas, os alunos já indicavam a reelaboração de alguns conceitos demonstrados quando o trabalho foi proposto, o que pode ser observado em observações como: "Eu pensei que todas as aldeias tinham forma circular!" (Caũ̃), "Nossa, como esses indios espalham sujeira no chão!" (Cauê) ou "Onde estão as casas de palha nessa aldeia?" (Apuena).

A visualização de índios vestidos com roupas de branco, bem como o acesso a notícias diversas sobre as etnias, levou à problematização da representação hegemônica indígena que descreve o índio como um indivíduo nu isolado na floresta, aproximando-o dos hábitos cotidianos dos sujeitos. O desenho de Araci pode ser utilizado como demonstrativo dessa problematização provocada pelo estudo empreendido nessa etapa. Nele, o índio apresenta semelhança física com um jovem branco, carrega uma sacola plástica e mora em uma casa de telhas e tijolos. Essa representação causou tal estranhamento aos sujeitos que levou Irajá a questionar: "Professora, será que esse desenho está certo, ele - o índio - está parecendo tão... normal!’.

Figura1: Representação gráfica da visão indígena antes e depois do desenvolvimento do trabalho de pesquisa - Araci, 2011.

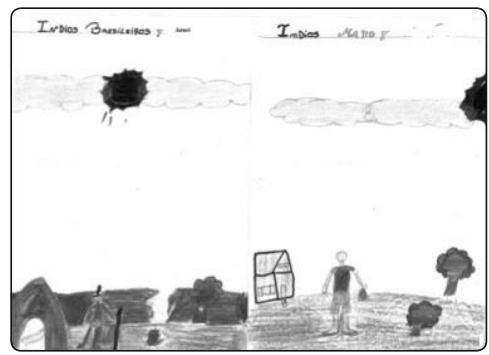

Normal foi um conceito utilizado com muita frequência pelo grupo, ora nos debates, ora nos relatos escritos. As transcrições a seguir demonstram o estranhamento dos 
sujeitos quando compararam seus hábitos ou atitudes aos dos grupos indígenas estudados: "As casas são normais (Ubirajara)", "plantam coisas que não são da sua origem que são: arroz, feijão, e cana-de-açúcar." (Iaciara), "moram em uma aldeia normal (Jaci)”, "usam roupas normais (Cendi)". Um debate sobre o conceito de normalidade permitiu concluir que grande parte do grupo conserva a visão eurocêntrica perpetuada na escola, pois quando questionados sobre qual o significado da palavra normal, respondiam peremptoriamente: "Iguais a nós!".

O conceito de "normalidade" foi bastante explorado ao longo do trabalho.

Durante uma das aulas, travou-se o seguinte debate:

IRAJÁ - Se eles são tão iguais à gente, por que não estudam aqui na nossa escola?

ABEGUAR - Eles estudam a mesma matemática que a gente?

IBIAJARA - A aldeia dos indios Kayapós não tem graça nenhuma, as casas são normais e usam roupas de gente comum.

O debate sobre o tema casas e roupas "normais" foi intenso, e o grupo foi categórico ao afirmar que normalidade é quando todos são "iguais a nós". Conforme está registrado no Diário de Campo (p. 21),

Intervi questionando quem era normal na sala, se entreolharam e responderam "todos". Continuei questionando se todas as roupas, pensamentos e casas eram iguais, aproveitando para comparar com os colegas "roqueiros" e "emos" da escola. Juntos, concluíram que "normal" não é sinal de igualdade, mas de hábitos e atitudes partilhados por grupos sociais que colaboram para sua inserção em determinado grupo.

Comparar-se aos índios e se descobrirem semelhantes a eles resultou em questionamentos significativos sobre as representações sociais indígenas constituídas na sociedade urbana.

Foi possível perceber, no discurso dos sujeitos, as práticas pedagógicas correntes de uniformização da figura indígena, desrespeitando as especificidades de cada etnia. Irajá expressa seu estranhamento quando, ao fim do debate, questiona: "Professora, se eles são tão iguais a nós, por que não estudam aqui na nossa sala?’.

A escola, quando apresenta as diversas etnias aos alunos simplesmente como indios, legitima o conceito de índio genérico, presente no senso comum e perpetuado socialmente (GRUPIONNI, 2001). Todavia, as etnias contemporâneas constituem uma imensa variedade, diversa e rica em conhecimentos, como alerta Grupioni (2001, p. 12): “O índio genérico não existe: existem povos distintos, com identidades próprias. Existem os bororó, os pataxó, os saterê-mawé e muitos outros grupos, cada um com seu próprio modo de ser e com sua maneira de ver o mundo".

Pastoriza (2011, p.61), ao analisar a origem de uma representação escolar, afirma:

[...] tanto ciência, quanto social, possuem um amplo corpo de conhecimentos e saberes que, no processo de didatização da Escola, vão sofrendo seleções, exclusões e inclusões de outros universos [...] que acabam criando uma forma de conhecimento específica [...]. Nessa perspectiva, compreendemos um movimento/processo descendente a partir do conhecimento científico - pois vai se tornando menos científico - e um movimento/ processo ascendente do 
senso comum - pois vai se constituindo de um conhecimento menos comum. (Grifo no original).

Esse processo de construção representacional e assimilações diversas foi constatado nas ações e relatos dos aprendizes e confirmou a estruturação de novas concepções a respeito das etnias, ainda que elas, em um primeiro momento, não apresentassem teor solidário ou cidadão.

Nessa etapa da pesquisa, a análise semiótica de suas representações gráficas permitiu detectar variações representacionais indígenas empreendidas pelos sujeitos: o bom selvagem foi substituído pelo indígena semelhante ao branco: $55 \%$ dos sujeitos passaram a desenhar o índio como um indivíduo aculturado - vestido com roupas de branco, por vezes frequentando supermercados; $28 \%$ dos sujeitos - todos pertencentes ao gênero masculino - associaram essa similaridade a maus bábitos, tais como: consumo de bebida, fumo ou porte de arma de fogo; $17 \%$ solidificaram a concepção do indio criança.

O desenho de Cauã atesta o ponto de vista da marginalização.

Figura 2: Representação gráfica de Cauã na qual o índio aculturado passa a se envolver com bebida e fumo.

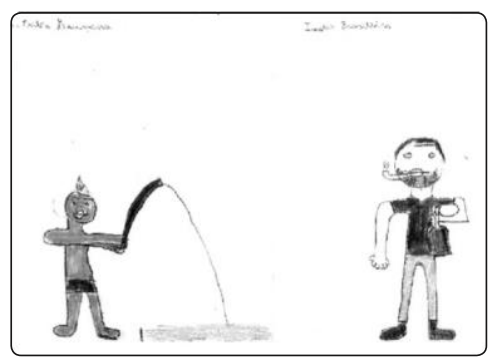

Essa imagem resume a influência das notícias divulgadas pela mídia e pelo senso comum, que interpretam o indígena como preguiçoso, consumidor de bebidas alcoólicas e sustentado pela caridade alheia.

A concepção do indio criança é descrita por Silva (1995, p.318) como uma concepção herdada do período colonial, quando os índios, considerados seres inferiores, representavam "o estágio da infância primitiva da humanidade." Essa concepção predominou em elementos pertencentes ao gênero feminino e pode ser exem-

plificada pelo discurso de Apuena: Depois que a gente fer a pesquisa, descobri que o indio é igual à gente, que não tem maldade e os brancos ficam querendo roubar o habitat deles; ou pelas palavras de Moema: $O$ meu sentimento por eles é bom e ruim, bom porque a gente pode ajudar eles a descobrirem as coisas modernas e ruim porque eles acreditam no papinho dos homens do mal.

Em seu discurso, os sujeitos associam essa visão de índio urbano ao conceito de vitimização, deixando transparecer o repúdio às técnicas de aculturação. Para exemplificar, segue o relato de Aisó, em defesa da permanência indígena nas florestas:

É um ambiente ótimo para os indios porque tem tudo o que eles precisam, lá eles fazem tudo que aprenderam, mas já se tivessem influência de bomens brancos, não seriam indios, mas homens brancos (negros,) existiria o dia do indio, mas não teria graça. Então é muito melhor deixar eles aonde estão, não tentar influenciar nossa lingua, 
nossos costumes pra eles porque é melhor. Eles até se acostumariam a trabalbar e vestir como nós, mas não seria correto com os indios.

Os educadores precisam reconhecer que a racionalidade é importante para os processos formativos, entretanto, somente ela não será suficiente para modificar "O imaginário e as representações coletivas negativas que se construíram sobre os ditos 'diferentes' em nossa sociedade" (BRASIL, 2007, p.07). É necessário suplantar a visão arcaica da escola que privilegia padrões culturais dominantes, elaborando novos objetivos, relacionados ao conhecimento e à valorização da diversidade cultural existente no território brasileiro.

A reformulação efetiva de concepções representacionais depende não só da identificação superficial detectada pelo grupo, mas também pressupõe a valorização das etnias indígenas como grupos detentores de saberes e direitos reconhecidos pela sociedade atual. Buscando esse reconhecimento, a próxima etapa didática dessa pesquisa envolveu a proposição de atividades cuja abordagem apoiava-se nos preceitos das etnociências.

\section{Etnociências e valorização da cultura indígena}

Campos (1995, p. 32) define as etnociências como um campo de diálogo no qual o conhecimento produzido pelo outro adquire status de ciência, ainda que seja diferente dos conceitos acadêmicos. Pode ser assim definida por resultar de uma construção de saber e conhecimento - etimologicamente, scientia deriva de scio (sei)- e, desafortunamente, "antes de entendermos a 'scientia' do outro nas relações homem/natureza, nos contaminamos com critérios 'científicos' de classificação hierárquica”. Dessa forma, a inserção das etnociências no currículo escolar pode se tornar uma estratégia para que os estudantes percebam os diferentes caminhos epistemológicos do conhecimento científico e a compreensão informada e crítica "da diversidade de formas de conhecimento construídas pela humanidade [...]" (BAPTISTA, 2007, p. 06). Ao reconhecer as populações indígenas como também detentoras de conhecimentos válidos, os sujeitos sentem-se instigados a desenvolver concepções mais positivas em relação a esses povos.

Conhecer e analisar as relações que os povos indígenas estabelecem com o ambiente pode levar a novas interpretações de conceitos biológicos importantes, como sustentabilidade, manejo ambiental e biodiversidade.

As florestas tropicais abrigam muitos povos indígenas e, simultaneamente, são os locais onde ocorrem os registros de maior biodiversidade (DIEGUES, 1999; CAMPOS, 1995; GRAY, 1995). O tênue equilíbrio entre conservação de espécies, manejo e sustentabilidade dos ecossistemas que ainda resistem a uma cultura predatória (CAMPOS, 1995) precisa ocorrer aliado ao conhecimento e ao respeito pelos saberes tradicionais e culturais desses povos que há anos sobrevivem em um ambiente identificado como hostil pela maioria dos indivíduos urbanos, e são guardiães de grande potencial biogenético (DIEGUES, 1999). Além disso, Posey (1986, p. 23) afirma que "o modo como os índios interagem com seu habitat oferece informações preciosas 
sobre as inter-relações ecológicas, todas elas cruciais para o funcionamento dos microecossistemas".

A resistência em considerar os conhecimentos tradicionais como válidos para a ciência contemporânea foi detectada no grupo de pesquisa, associada ao pensamento dominante que considera o índio um ser primitivo, inocente e desmerecedor de credibilidade. Alguns sujeitos reagiram imediatamente quando da proposição da pesquisa, relacionando a temática indígena a "coisas de criança", que gostam de se fantasiar, cantar e dançar. Yara, Cauã e Abati afirmaram veementemente que a temática não "tem nada a ver com ciências". O grupo reagiu de maneira agitada, cantaram músicas infantis, simularam atirar arco e flecha e relacionaram a temática às aulas de história, demonstrando incompreensão sobre a possibilidade de interação entre as duas disciplinas, tendo esse tema como ponto de partida.

Buscando discutir a visão pedagógica eurocêntrica, nessa etapa do trabalho os educandos investigaram as relações cosmológicas das etnias com o meio ambiente, por meio do estudo de lendas; compararam os critérios de classificação taxonômica indígena e lineísta?; e empreenderam atividades de leitura de textos que descreviam técnicas agrícolas indígenas, discutindo-os.

A utilização de textos diversos de abordagem etnográfica (DESCOLA, 1998; POSEY, 1986; RIBEIRO, 1986) permitiu não apenas o aprofundamento dos conhecimentos sobre seres vivos, o desenvolvimento de conceitos ecológicos importantes e discussões envolvendo práticas agrícolas, mas também acrescentou alguns pontos importantes para a discussão sobre a construção representacional indígena. As representações gráficas dessa etapa da pesquisa trouxeram alguns componentes instigantes:

- 95\% dos desenhos produzidos mostravam um indivíduo isolado em contato com o meio ambiente, descartando uma das características mais marcantes das etnias indígenas: a convivência em grupos.

- 56,5\% dos sujeitos representaram o índio vestido de tanga na floresta, a despeito das construções representacionais elaboradas anteriormente, nas quais a totalidade do grupo desenhou personagens vestidos de bermudas e camisetas, como se, ao se utilizar dos recursos naturais, o índio voltasse ao estereótipo aparentemente superado na primeira etapa do trabalho. Algumas produções acusaram a dificuldade em abandonar definitivamente as representações sociais indígenas arraigadas. Bachelard (1971, p. 125) descreve essa situação como característica do processo epistemológico de construção do conhecimento científico:

O espírito tem uma estrutura variável, a partir do momento em que o conhecimento tem uma história. Com efeito, a história humana, nas suas paixões, nos seus preconceitos, em tudo que depende das impulsões imediatas, pode bem ser um eterno recomeço; mas há pensamentos que não recomeçam: são os pensamentos que foram rectificados, alargados, completados. Não retornam à sua área restrita ou vacilante. [...]. A sua estrutura é a consciência dos seus erros históricos. Cientificamente considera-se o verdadeiro como retificação histórica de um longo erro, $[\ldots]$. 
Segundo Grupioni (1994), a inserção da cosmologia indígena e do conhecimento de suas práticas tradicionais no currículo educacional não se trata de um mecanismo para incorporação dessas crenças, mas para tomá-las como um referencial pedagógico. Mais do que aceitar o conhecimento indígena como se fosse o modelo correto de relacionamento com a natureza, o estudo visa proporcionar problematizações nos hábitos e atitudes dos educandos e trazê-los para o campo da discussão educacional, transformando-os em objetos a conhecer (BACHELARD, 1971) que permitam reconstruir um conhecimento ambiental livre de preconceitos ou ações fundamentalistas.

Aparentemente, as atividades de estudo etnográfico desenvolvidas provocaram um retrocesso na construção representacional indígena, pois os sujeitos, em sua maioria, retomaram o conceito de bom selvagem. Buscando vencer essa dificuldade, foi proposta outra atividade que propiciasse a inserção dos aprendizes no contexto indígena contemporâneo, levando-os a participar de uma visita a uma aldeia Kaingang localizada em um município próximo ao da escola.

Bachelard (1996, p.10) afirma: "ninguém pode arrogar-se o espírito científico enquanto não estiver seguro, em qualquer momento da vida, do pensamento, de reconstruir todo o próprio saber." A visita à aldeia indígena despertou esse interesse dos alunos, abrindo caminho para a reformulação de representações sociais históricas e reformulações no saber sobre a cultura indígena brasileira contemporânea.

A saída de campo foi válida para auxiliar os educandos a superarem a representação do indígena selvagem e isolado do contexto urbano. Após essa atividade, 70,5\% dos sujeitos passaram a se preocupar em identificar as etnias em suas produções e a referirse aos índios no plural. Chauí (1992, p. 12) relaciona a designação no plural ao contexto diversificado indígena em oposição à representação do indio genérico - inexistente.

Seniciato e Cavassan (2004, p.133) atestam a contribuição pedagógica dos trabalhos em campo para as aulas de ciências ao afirmarem que:

[...] as aulas de Ciências e Biologia desenvolvidas em ambientes naturais têm sido apontadas como uma metodologia eficaz tanto por envolverem e motivarem crianças e jovens nas atividades educativas, quanto por constituírem um instrumento de superação da fragmentação do conhecimento.

Compartilha-se esse ponto de vista e, no caso específico dessa pesquisa, é possível acrescentar a relevância da visita à aldeia para a consolidação de representações indígenas relacionadas à identificação recíproca dos aprendizes com os habitantes daquele espaço, o que levou à completa superação da concepção hegemônica do bom selvagem e ao reconhecimento dos índios como cidadãos com hábitos, direitos e deveres semelhantes aos do indivíduo urbano. A transcrição do diálogo, empreendido entre Araci, Ubirajara, Ayira e a diretora da escola, quando retornamos da aldeia, permite identificar essa reconstrução:

Diretora: E aí, o que vocês viram na aldeia?

Araci: Eles têm Sky no telhado, TV s de tela plana em suas casas e na escola, computadores...

Ubirajara: Ah, e não pode esquecer que eles têm vídeo-game em suas casas.

Ayira: E vocês jogaram bola com os garotos indios e perderam de lavada. 
0 ensino de Ciências como ferramenta pedagógica de reconstrução das representações escolares sobre os povos indígenas

Diretora: Então não tem graça, en pensei que vocês iam ver os indios nas ocas, igual nos livros. Araci: $A i$, "sora", isso não existe mais, eles não são bichos pra ficar no zoológico pra gente ir olhar, eles são gente que nem a gente.

\section{CONSIDERAÇÕES FINAIS}

A história brasileira foi construída sobre a neutralização, escravização ou extermínio da cultura indígena. Atualmente, é comum nos depararmos com relatos de conflitos e desrespeito em relação aos variados grupos indígenas que ainda habitam o território nacional, e essas notícias negam a inclusão desses elementos na constituição da identidade nacional.

As etnias indígenas interagem com os elementos naturais por meio do uso, da convivência, da cosmologia e dos saberes culturais adquiridos ao longo dessa relação. A compreensão dessa interação é um processo complexo e de difícil entendimento para os educandos, habituados com a concepção eurocêntrica padrão, existente nas sociedades urbanas.

Estereótipos derivados de representações sociais históricas constituem-se em obstáculos epistemológicos² (BACHELARD, 1996) ao processo de reconhecimento à diversidade cultural indígena e para superá-los, faz-se necessário uma imersão racional e objetiva nesse contexto etnográfico. Esse processo gradual, dinâmico e instigante auxilia os educandos a desenvolverem novos hábitos e atitudes expressos por um discurso solidário.

Representações relacionam-se à interpretação do ambiente, derivada da leitura que o aprendente faz de seu entorno sociocultural e que parte da experiência e simbologia particulares de cada um. O educando lança mão de sua realidade e dos conhecimentos assimilados para compor representações coerentes com sua experiência pessoal. Nem sempre ocorre fidedignidade entre as representações e as concepções que lhes fundamentam, uma vez que as concepções mobilizam o saber pré-existente para que ocorram adaptações a novos problemas e situações vivenciadas. Por vezes, tal ação sofre influência do conhecimento anterior em detrimento da nova informação, permanecendo o saber consolidado, ainda que esteja ligeiramente modificado por necessidade de solucionar o novo problema. As reformulações representacionais são idiossincráticas, obedecem ao tempo e ao interesse de cada sujeito. A temática trabalhada influenciou o agir e o pensar dos indivíduos, produzindo novas representações escolares, alicerces para a construção de uma representação indígena genuinamente cidadã.

A maioria dos sujeitos da pesquisa, depois do complexo trabalho desenvolvido, das investigações empreendidas e das abordagens diversas utilizadas, evoluiu em suas representações sobre os indígenas. Os alunos modificaram concepções que oscilavam entre indiferença, temor e compaixão para uma representação alteritária de aceitação e orgulho. Desmistificaram o índio heroico ou aterrorizante, reconhecendo os indígenas como indivíduos detentores de direitos e deveres cidadãos.

A imagem heroica do índio, de certa forma construída pelo movimento modernista, impede que essas etnias sejam encaradas como objeto de estudo quando o tema 
abordado recorre à pluralidade cultural. Nesse caso, a maioria dos trabalhos envolvendo esse tema refere-se aos negros. Os povos indígenas brasileiros contemporâneos raramente são considerados e, quando o são, um véu de ingenuidade e vitimização os encobre. Alguns sujeitos, mesmo após o trabalho de pesquisa desenvolvido, substituíram o preconceito relacionado ao índio selvagem pelo preconceito do índio marginal. Os povos indígenas eram marginalizados porque viviam na floresta. Hoje, para esses educandos, permanecem marginalizados nas cidades e pelas disputas territoriais.

Reconhecer, respeitar e valorizar uma cultura que parece estar distante temporal e geograficamente do cotidiano não é fácil. Pressupõe conhecimento cuidadoso, identificação e apropriação dos elementos que a constituem. Assim, o trabalho aqui apresentado não pode ser considerado como concluído. Muitos são os degraus que devem, ainda, ser galgados em direção ao processo de cidadania elaborada a partir do conhecimento da cultura indígena, com vistas à formação de uma sociedade ética, equitativa e solidária. A desconstrução de preconceitos demanda novos estudos e pesquisas, como o enfoque trans e interdisciplinar do tema, os aspectos mitológicos da cosmologia indígena e o aprofundamento sobre a Educação Ambiental.

Abordar a temática indígena em todos os níveis da educação, seja ela básica, superior ou junto aos docentes, é uma recomendação legal - Lei 11.645/08 - e necessita de atenção para que ocorra a construção de uma identidade cultural brasileira genuína subordinada ao reconhecimento da influência cultural indígena na constituição da população brasileira contemporânea. Esse reconhecimento depende da identificação com os hábitos e costumes desses grupos étnicos, o que poderá levar a uma concepção de indio renovada, solidária, possibilitando, assim, "atribuir aos índios um lugar efetivo e digno como cidadãos de um país, cuja plena cidadania só pode ser definida e construída por um viés plural, [...].” (GRUPIONI, 2001, p. 23).

\section{NOTAS}

1 "Sensoriamento remoto é um termo utilizado na área das ciências aplicadas que se refere à obtenção de imagens à distância, sobre a superfície terrestre.” (RUDORFF, 2011).

2 Obstáculo Epistemológico - OE- é um conceito epistemológico proposto por Gaston Bachelard, segundo o qual os OE são elaborados ao longo da vida dos indivíduos, a partir de sua experiência social e educativa. A aprendizagem efetiva decorre de sua superação.

\section{REFERÊNCIAS}

ANDRÉ, M. Estudo de caso: seu potencial na educação. Cadernos de Pesquisa, São Paulo, n. 49, p. 51 54. maio 1984.

ARRUDA, A. O ambiente natural e seus habitantes no imaginário brasileiro: negociando a diferença.

In: ARRUDA, A. (Org.) Representando a alteridade. 2. ed. Petrópolis: Vozes, 2002.

BACHELARD. G. A formação do espirito cientifico. Rio de Janeiro: Contraponto, 1996. . Epistemologia. Textos organizados por Dominique Lecourt. Lisboa: Setenta, 1971. 
0 ensino de Ciências como ferramenta pedagógica de reconstrução das representações escolares sobre os povos indígenas

BANIWA, G. O indio brasileiro: o que você precisa saber sobre os povos indígenas no Brasil de hoje. Brasília: MEC/UNESCO. 2006.

BAPTISTA, G. C. S. A contribuição da etnobiologia para o ensino e a aprendizagem de ciências: estudo de caso em uma escola pública do estado da Bahia. 2007. 188f. Dissertação de Mestrado em Ensino, Filosofia e História das Ciências. Universidade Federal da Bahia, Salvador, 2007.

. Conhecimentos prévios sobre a natureza, prática de ensino e formação docente em ciências.

Revista da FAEEBA: educação e contemporaneidade, Salvador, 2006. v. 15, n. o 26, p. 199-210.

BARTHES, R. Elementos de semiologia. São Paulo, Cultrix, 1971.

BRASIL. Secretaria de Educação Fundamental. Parâmetros curriculares nacionais: pluralidade cultural, orientação sexual. Brasília: MEC/SEF, 1997.

. Lei 11.645/ 08. Diário Oficial da República Federativa do Brasil. Disponível em: <http://www. planalto.gov.br/ccivil_03/_Ato2007-2010/2008/Lei/L11645.html>. Acesso em: 2 de jun. 2011.

. Programa de Desenvolvimento Continuado: construindo valores na escola e na sociedade: relações étnico-raciais e de gênero- Módulos: 1, 2, 3 e 4. Brasília: Ministério da Educação, Secretaria de Educação Básica, 2007.

CAMPOS, M.D. Sulearium: sociedade e natureza: da etnociência à etnografia de saberes.1995.

Disponível em: <http://www.sulear.com.br/texto04.pdf>. Acesso em: 11 de nov. 2012.

CHAUÍ, M. S. 500 Anos - Caminhos da Memória, Trilhas do Futuro. In: GRUPIONI, L.D.B. Indios no Brasil. Brasília: Ministério da Educação e Cultura, 1994.

DESCOLA, P. Estrutura ou Sentimento: a relação com o animal na Amazônia. Mana. vol. 4, n.1, p. 2345, 1998.

DIEGUES, A. C. Os saberes tradicionais e a biodiversidade no Brasil. São Paulo: USP, 2000.

FOCALIZA ISSO! Dicionário de significado de nomes. Disponível em: $<$ http:// focalizaisso.com.br/component/ option,com_name_meaning/Itemid,77/task,search/origin,12/> . Acesso em: 10 mar. 2011.

HALL, S. The work of representation. In: HALL, Stuart. Representation: cultural representations and signifying practices. London/Thousand Oaks/New Delhi: Sage/The Open University, 1997.

GRAY, A. O impacto da conservação da biodiversidade sobre os povos indígenas. In: SILVA, A. L; GRUPIONI, L.D.B. (Org) A temática indígena na escola: novos subsídios para professores de $1^{\circ} \mathrm{e} 2^{\circ}$ graus. Brasília: MEC/MARI/UNESCO, p. 109-128 , 1995.

. As sociedades indígenas no Brasil através de uma exposição integrada. In: GRUPIONI, L.D.B. Índios no Brasil. Brasília: Ministério da Educação e Cultura, p. 13-28, 1994.

GRUPIONI, L.D.B. Índios: passado, presente e futuro. In: BRASIL. Índios no Brasil. 2001. Cadernos da TV Escola. p. 07-36. 2001

GUSMÃO, N. M. M. de. Linguagem, cultura e alteridade: imagens do outro. 1999. Cadernos de Pesquisa, São Paulo, n. 107, p.41-78, jul.

IBGE. Instituto Brasileiro de Geografia e Estatística. População indigena. Disponível em: <http:// www.ibge.gov.br/home/presidencia/noticias/noticia_visualiza. php?id_noticia $=2119 \& i d \_$pagina $=1>$. Acesso em: 17 ago. 2012.

KOEPPE, C. H. B.; LAHM, R. A.; BORGES, R. M. Usina hidrelétrica de Belo Monte: uma polêmica atual para despertar a educação ambiental crítica. Experiências em Ensino de Ciências, Cuiabá, v.8. n.1. p. 17-28, abr. 2013.

KREUTZ, L. Identidade étnica e processo escolar. Cadernos de Pesquisa, São Paulo, n.107, p.79-96, jul.1999.

MORAES, R.; GALIAZZI, M. C. Análise textual discursiva. Ijuí: UNIJUÍ, 2007.

NOVAES, A. (Org). A outra margem do ocidente. São Paulo: Companhia das Letras, 1999.

PASTORIZA, B. Representações escolares: produção e constituição de formas de conhecimento em educação em ciências. 2011. 167 f. Dissertação (Mestrado em educação em Ciências: Química da vida e saúde) Instituto de Ciências Básicas da Saúde, Universidade Federal do Rio Grande do Sul, Porto Alegre. 2011.

POSEY, D. Introdução - Etnobiologia: teoría e prática. In: RIBEIRO, B. (Org.) Suma etnológica brasileira: 1 Etnobiologia. Petrópolis: Vozes, 1986. p. 15- 25. 
RIBEIRO, B. A contribuição dos povos indígenas à cultura brasileira. In: SILVA, A. L.; GRUPIONI,L.

D. B. (Org.) A temática indígena na escola: novos subsídios para professores de 1 e 2 graus. Brasilia: MEC/Mari/UNESCO, 1995. p. 197 -219.

SANTOS, J. M.; LAHM, R. A., BORGES, R. M.R. O sensoriamento remoto como recurso para a

Educação Cientifica e Tecnológica. In: BORGES, R. M. R; BASSO, N. R.; ROCHA FILHO, J. B. Propostas interativas na educação cientifica e tecnológica. Porto Alegre: EDIPUCRS, 2008.

SENICIATO, T.; CAVASSAN, O. Aulas de campo em ambientes naturais e aprendizagem em ciências um estudo com alunos do ensino fundamental. Ciência \& Educaşão, Bauru, 2004. v. 10, n. 1, p. 133-47.

TASSINARI, A. M. I. Sociedades indígenas: introdução ao tema da diversidade cultural. In: SILVA, A. L.; GRUPIONI, L. D. B. (Org.). A temática indígena na escola: novos subsídios para professores de 1 e 2 graus. Brasília: MEC/Mari/UNESCO, 1995. p. 445-479.

TREZ, T.A. Feyerabend, interculturalismo e etnobiologia: algumas possíveis articulações no ensino de Biologia. Biotemas, Florianópolis, 2011. n. 24. Vol.3. p.129-140. 